\title{
Predicting warming-induced hypoxic stress for fish in a fragmented river channel using ecosystem metabolism models
}

\author{
Jacob P. Ziegler, James W. Roy, Matthew J. Bogard, and D. Andrew R. Drake
}

\begin{abstract}
Aquatic biota often face multiple anthropogenic threats such as river fragmentation and climate change that can contribute to high rates of aquatic species imperilment world-wide. Temperature-induced hypoxia is one under-explored mechanism that can threaten aquatic species in fragmented rivers with reduced flows. We applied ecosystem metabolism models to define the effect of water temperature on net ecosystem production (NEP) of oxygen at 12 sites of a fragmented river channel that supports three fish species at risk and experiences hypoxia. We found that water temperature and precipitation events at $75 \%$ of our sites were significantly and negatively correlated to NEP estimates and explained $28 \%$ of the variation in NEP within sites. Temperature-induced reductions in NEP at these sites likely contributed to hypoxic conditions threatening the three species at risk as NEP explained $41 \%$ of the variation in dissolved oxygen near all sites. Our results have applications for understanding drivers of hypoxic stress in fragmented watercourses, integrating water temperature-NEP effects with oxygen demands of sensitive fish species, and modeling future effects of climate change on aquatic species.
\end{abstract}

Résumé : Les organismes aquatiques font souvent face à de multiples menaces d'origine humaine telles que la fragmentation des rivières et les changements climatiques qui peuvent contribuer à accélérer les risques pour les espèces aquatiques partout sur terre. L'hypoxie induite par la température est un mécanisme sous-exploré qui peut menacer les espèces aquatiques dans les rivières fragmentées présentant des débits réduits. Nous utilisons des modèles de métabolisme écosystémique pour déterminer l'effet de la température de l'eau sur la production écosystémique nette (PEN) d'oxygène en 12 sites du chenal d'une rivière fragmentée qui soutient trois espèces de poissons en péril et dans laquelle des conditions hypoxiques sont observées. Nous constatons que la température de l'eau et les épisodes de précipitations dans 75 \% des sites étudiés présentent des corrélations négatives significatives avec la PEN estimée et expliquent $28 \%$ des variations de la PEN à l'intérieur des sites. Les baisses de PEN induites par la température dans ces sites participent probablement aux conditions hypoxiques qui menacent les trois espèces en péril, puisque la PEN explique $41 \%$ des variations des teneurs d'oxygène dissous à proximité de tous les sites. Nos résultats sont importants pour la compréhension des moteurs du stress hypoxique dans les cours d'eau fragmentés, l'intégration des effets de la température de l'eau sur la PEN aux besoins en oxygène d'espèces de poissons sensibles et la modélisation des effets futurs des changements climatiques sur les espèces aquatiques. [Traduit par la Rédaction]

\section{Introduction}

Ecosystem fragmentation and reduced river flow are widespread anthropogenic impacts that threaten aquatic biodiversity globally. Dynesius and Nilsson (1994) estimated that $77 \%$ of the total discharge from large rivers in the Northern Hemisphere was affected by river fragmentation due to dams, diversion, or irrigation, while Grill et al. (2019) estimated that $63 \%$ of large rivers globally have undergone fragmentation and resulting losses of connectivity. One effect of river fragmentation that is common among human-modified river systems is reductions in river flow and turbulent mixing (Poff et al. 2007; Döll et al. 2009). Reduced river flow has likely contributed to biodiversity declines in these systems (Poff et al. 1997; Stanford and Nelson 1997; Bunn and Arthington 2002). While there have been efforts to restore riverine systems, species recovery has remained challenging (Palmer et al. 2014; Lorenz et al. 2018; Palmer and Ruhi 2019), prompting calls to take an ecosystem-level approach for restoration of riverine processes by addressing the root causes of deterioration (Beechie et al. 2010; Palmer and Ruhi 2019). While our understanding of the mechanisms underlying biodiversity declines with reduced flow has improved, research has focused mainly on changes to channel morphology, disrupted phenologies of aquatic species, increased isolation of populations, and improved conditions for aquatic invasive species (Poff et al. 1997; Stanford and Nelson 1997; Bunn and Arthington 2002). However, the stressor of hypoxia, which threatens the ability of aquatic species to cope with environmental demands and can be widespread in watercourses with reduced flow and turbulent mixing, has received less attention.

While hypoxic conditions (low oxygen concentrations) naturally occur in aquatic systems, anthropogenic activities like reduced water flows and circulation have increased the prevalence of hypoxia (Diaz and Breitburg 2009). Some published studies and water quality regulations have focused on threshold values (often

Received 24 December 2020. Accepted 8 May 2021.

J.P. Ziegler and D.A.R. Drake. Great Lakes Laboratory for Fisheries and Aquatic Sciences, Fisheries and Oceans Canada, Burlington, Ont., Canada. J.W. Roy. Water Science and Technology Directorate, Environment and Climate Change Canada, Burlington, Ont., Canada.

M.J. Bogard.* Department of Biological Science, University of Lethbridge, Lethbridge, Alta., Canada.

Corresponding author: Jacob P. Ziegler (email: Jacob.Ziegler@dfo-mpo.gc.ca).

${ }^{*}$ Matthew J. Bogard served as an Associate Editor at the time of manuscript review and acceptance; peer review and editorial decisions regarding this manuscript were handled by Paul Venturelli.

() 2021 Bogard and Her Majesty the Queen in Right of Canada. This work is licensed under a Creative Commons Attribution 4.0 International License (CC BY 4.0), which permits unrestricted use, distribution, and reproduction in any medium, provided the original author(s) and source are credited. 
5-6 mg. $\mathrm{L}^{-1}$ ) for defining hypoxia in freshwater habitats; however, these thresholds are not always informative as oxygen requirements of aquatic species differ widely among species and life stages (Diaz and Breitburg 2009). Therefore, interest in physiological metrics like aerobic scope (the difference between an individual's base and maximum metabolic rate at a given environmental condition), is increasing, in that aerobic scope can provide a species and life stage specific metric of the ability to cope with environmental demands and sensitivity to stressors like hypoxia and temperature (Fry 1971; Clark et al. 2013).

The external drivers of dissolved oxygen (DO) in rivers are turbulent mixing at the air-water interface (reaeration) and DO in groundwater. Reaeration in rivers and streams is determined mainly by flow velocity (Owens et al. 1964; Tsivoglou and Neal 1976; Ulseth et al. 2019). Reduced river flow velocity associated with modified systems can lead to less reaeration and, therefore, lower river DO. Groundwater discharge, another external driver of DO (Hall and Tank 2005), can have oxygen content ranging from air-equilibrated to completely anoxic (e.g., Roy and Malenica 2013). Inputs of low-DO groundwater will contribute to river hypoxia, while inputs of high-DO groundwater will oppose hypoxia; both will have a greater influence during low river flows. Therefore, the net effect of groundwater on surface DO dynamics is unclear in a whole ecosystem context.

The most important internal processes controlling dissolved oxygen within a river are primary production and respiration. Both will be affected by increased water temperatures, which can result from lower flows and higher air temperatures (Webb et al. 2003). Ecosystem metabolic responses to temperature show universal patterns among diverse river ecosystems (Demars et al. 2011, 2016; Yvon-Durocher et al. 2012; Song et al. 2018). At the ecosystem level, activation energies of gross primary production and respiration rates differ, which characterizes the sensitivity of the respective rates to temperature. Rates of gross primary production show a more muted response to temperature than do rates of respiration (Yvon-Durocher et al. 2010; Regaudie-de-Gioux and Duarte 2012; Schramski et al. 2015); therefore, at higher temperatures the mass-specific rate of respiration is often higher than gross primary production (Yvon-Durocher et al. 2010) and can lower rates of net ecosystem production (NEP) and net oxygen cycling (Yvon-Durocher et al. 2010; although see Demars et al. 2016). Despite the potential usefulness of ecosystem metabolism models for predicting hypoxic stress for freshwater species at risk, to the best of our knowledge, they have not been applied or evaluated in this context (although see Genzoli and Hall 2016 and Arroita et al. 2019).

It is unclear if increases in water temperature will always predict hypoxic stress for aquatic species as temperature-induced reductions in NEP can be complicated by spatial and temporal variation in other factors that affect NEP (Bogard et al. 2020). Yvon-Durocher et al. (2012) demonstrated a universal positive relationship between ecosystem respiration and temperature by controlling for site-specific covariates within an ecosystem using mixed effects models. However, when predicting hypoxia, sitelevel variation is relevant (Jankowski et al. 2014) as aquatic species do not experience an average oxygen concentration across the ecosystem, but rather, conditions at the site. Therefore, sitelevel relationships of NEP and temperature must be explicitly modeled, rather than controlled for, to determine if temperature is a consistent predictor of NEP throughout an ecosystem, or if site-specific predictors of NEP are required. Nutrients and allochthonous carbon are two site specific predictors of NEP (Del Giorgio et al. 1999; Enquist et al. 2003; Mallin et al. 2006; Solomon et al. 2011; Jankowski et al. 2014; Sitters et al. 2015) and both vary spatially and over time within a system, due to factors such as precipitation, runoff and groundwater inputs (Sitters et al. 2015).

Here we apply ecosystem metabolism models to determine if temperature-induced shifts toward heterotrophy (i.e., negative $\mathrm{NEP}$ ) is a contributing factor threatening three fish species at risk in a fragmented river channel with reduced flows that experiences summer and winter hypoxia. We explicitly modeled the effect of water temperature on relative changes in NEP at 12 sites within the river reach to determine if NEP-temperature relationships were consistent among sites within the watercourse or if there were other site-specific factors that need to be considered in addition to water temperature, that can confound the NEPtemperature relationship among sites. We also tested the ability of NEP to predict hypoxic conditions throughout the river reach over time. Oxygen inputs via reaeration were explicitly calculated based on windspeed, while the potential bias in metabolism estimates due to groundwater was estimated following Hall and Tank (2005).

Our study system is the Old Ausable Channel (OAC) northwest of London, Ontario, Canada. The watercourse was reduced to a low-flowing 14-km channel by several river diversions (Fig. 1). The OAC contains three fish species at risk in Canada. These species are sensitive to hypoxic conditions that the system regularly experiences (Fig. 2) as indicated by field observations that prolonged hypoxia has resulted in large mortality events of these and other species. Therefore, a better understanding of the factors controlling DO supply and demand in this and other ecosystems is needed to inform restoration of biological function in river channels experiencing periods of hypoxic stress.

\section{Methods}

\section{Study system}

The Old Ausable Channel (OAC) was created at the end of the 19th century when Parkhill Creek was purposely diverted to Lake Huron, rather than flowing south to meet the Ausable River (Fig. 1). This anthropogenic separation of the Ausable River (now known as the $\mathrm{OAC}$ ) from the flowing system and lack of any tributary inputs means it is predominantly supplied by surface run-off and some groundwater discharge. The volume of groundwater discharge is generally low given a small watershed area, small water table gradients, and a decrease in the surficial aquifer thickness within the northern reach of the watercourse (Schincariol et al. 2004). The watercourse becomes stagnant throughout the summer outside of rain events and storms. Schincariol et al. (2004) estimated a baseflow discharge of $0.09 \mathrm{~m}^{3} \cdot \mathrm{s}^{-1}$ for the OAC using dilution gaging and calculated a flow velocity of only $0.002 \mathrm{~m} \cdot \mathrm{s}^{-1}$ at this discharge. The surface area of the OAC is $0.531 \mathrm{~km}^{2}$ with a stream reach of $13.5 \mathrm{~km}$. During our study period, the average wetted width and depth of the OAC was 39 and $1.0 \mathrm{~m}$, respectively. Installation of a small dam mid-channel in 1962 has resulted in lower flow velocity in the northern section due to pooling behind the dam (Fig. 1). The OAC supports a diverse submerged macrophyte community with an average percent cover of $83 \%$ that is similar among sites from upstream to downstream (Schincariol et al. 2004). Therefore, the relative contribution of submerged macrophytes to primary production is likely similar throughout the OAC.

The OAC contains a diverse warm-water fish community, including three fishes listed under Canada's Species at Risk Act (lake chubsucker (Erimyzon sucetta), Endangered; pugnose shiner (Notropis anogenus), Threatened; and grass pickerel (Esox americanus vermiculatus), Special Concern). Although most warm-water fishes are not widely regarded as being sensitive to hypoxia, field collections have revealed large-scale die-offs, including Lake Chubsucker (K. Jean, Ausable Bayfield Conservation Authority, unpublished data), raising concerns that the intensity and (or) duration of hypoxia in the system may be sufficiently large to cause widespread mortality. As indicative of many species at risk worldwide, these species face multiple threats from human activities, such as largescale modification and fragmentation of their habitat and increased water temperatures from climate change and surrounding urbanization. 
Fig. 1. Map depicting our study system, the Old Ausable Channel, including the location of sites where net ecosystem production was estimated, and the location of depth loggers and weather stations used in estimating net ecosystem production. This map was reproduced with permission from the Ausable Bayfield Conservation authority and created with Inkscape (Inkscape Project 2020). [Colour online.]

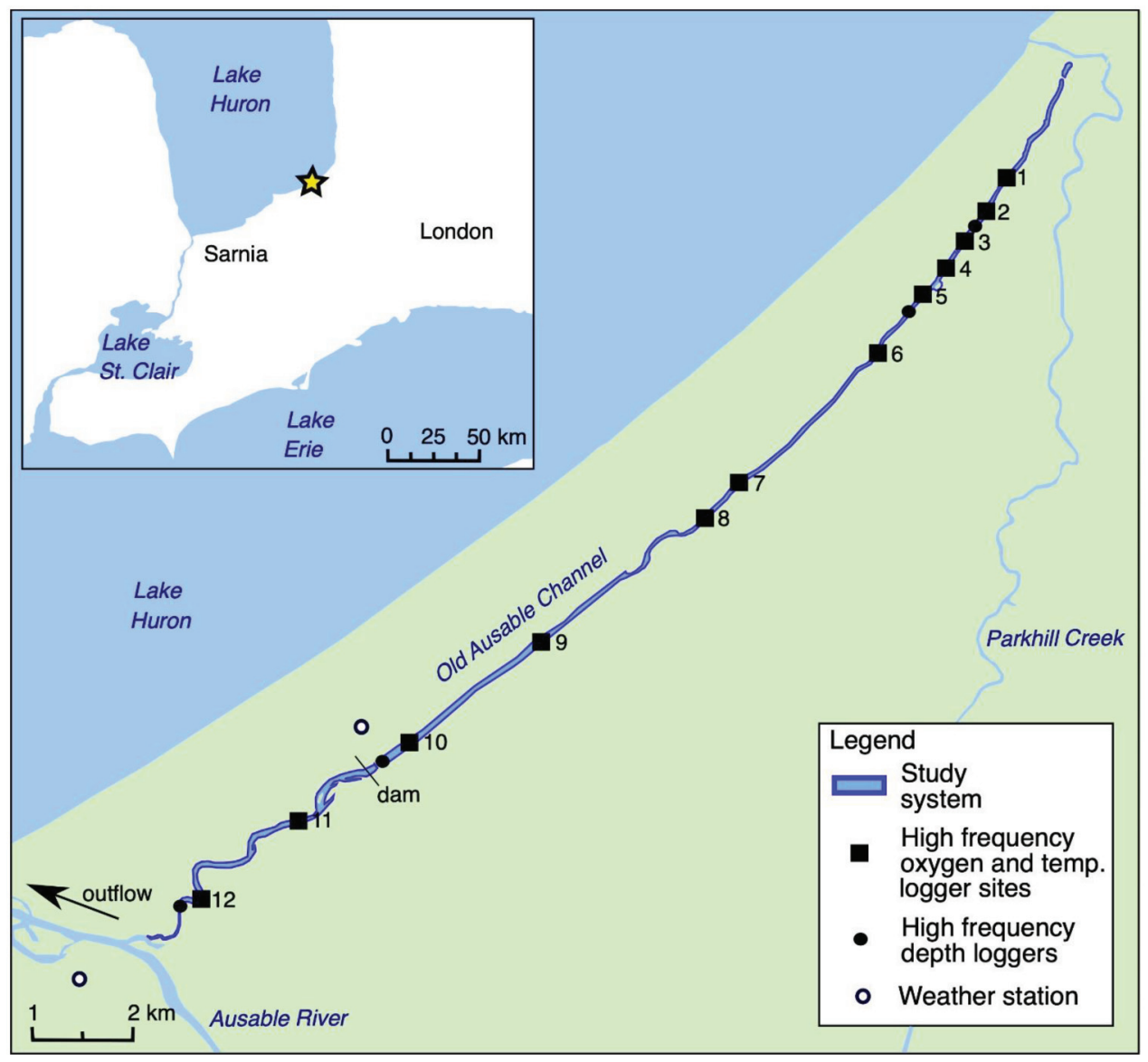

\section{Field measurements}

Continuous measurements of oxygen and temperature were made at 12 sites spread across the OAC (Fig. 1) from February 2017 to November 2018 using high frequency (15 to 30 min intervals) MiniDOT oxygen and temperature loggers. These were deployed below floats to target the lower third of the water column. Given the shallow depth of the watercourse $(1.0 \mathrm{~m}$ on average over the study period) and the clear water conditions (i.e., low light attenuation with depth), the water column was unlikely to be stratified. For example, in lakes the shallowest thermoclines are observed in dark lakes with high dissolved organic carbon and, therefore, high light attenuation with depth (Pérez-Fuentetaja et al. 1999). Pérez-Fuentetaja et al. (1999) found that lakes with the highest dissolved organic carbon and shallowest thermocline depth still had thermocline depths of at least $3 \mathrm{~m}$ (i.e., deeper than any recorded OAC depth over the study period). However, some loggers likely came in contact with the sediment on a few occasions, resulting in erroneous data (continuous $0 \mathrm{mg} \cdot \mathrm{L}^{-1}$ readings), as discussed below. Spot measurements of DO and temperature were made at 72 sites spread evenly across the OAC (Fig. 2), including the logger locations, using YSI hand-held meters on a biweekly basis. Spot measurements at logger locations were used to verify that there was no drift in logger DO readings over time (see Supplementary material, Fig. S4 ${ }^{1}$ ). Stream stage depth was measured using high frequency (15 min intervals) depth loggers at 4 sites (Fig. 1).

\section{Estimating net ecosystem production}

We estimated daily stream net ecosystem production (NEP, $\mathrm{g} \mathrm{O}_{2} \cdot \mathrm{m}^{-2} \cdot \mathrm{day}^{-1}$ ) at each site using the continuous dissolved oxygen and temperature data. Oxygen typically increases during the day due to photosynthesis outpacing respiration, and decreases at night due to respiration outpacing any diffusion of oxygen into the water. Therefore, we further investigated instances of $0 \mathrm{mg} \cdot \mathrm{L}^{-1}$ dissolved oxygen readings over a 24 -hour period to determine if these were inaccurate readings. Spot measurements at these same locations were never $0 \mathrm{mg} \cdot \mathrm{L}^{-1}$ during the duration of the study (Fig. 2); therefore, instances of $0 \mathrm{mg} \cdot \mathrm{L}^{-1}$ dissolved oxygen readings over a 24-hour period were likely due to logger error or contact of the logger with the sediment. As a result, we removed these instances from our analyses. Nearly all instances occurred during the winter when loggers were under ice, restricting our analyses to the open water season (i.e., when the OAC was ice free).

Given that our sites were spaced over greater distances than the DO turnover lengths within the OAC (see Supplemental Information Table $S 1^{1}$ ) and our focus on within-site NEP (not among site NEP comparisons), we used the single station diel oxygen curve method for estimating daily NEP at each site (Bott 2006). This method measures the daily net oxygen production by photosynthesis $(\mathrm{NEP}>0)$ or consumption by respiration $(\mathrm{NEP}<0)$ after correcting for oxygen exchange with the atmosphere (for step by step calculations see table 28.2 in Bott 2006). This method is 
Fig. 2. Point measurements of dissolved oxygen (DO) during the open water season at 72 sites in the Old Ausable Channel taken approximately biweekly from February 2017 to October 2018. The bold line represents the mean of multiple DO observations among sites on a given day to highlight trends in DO over the year. The gap in measurements indicates the period when the channel was ice-covered.

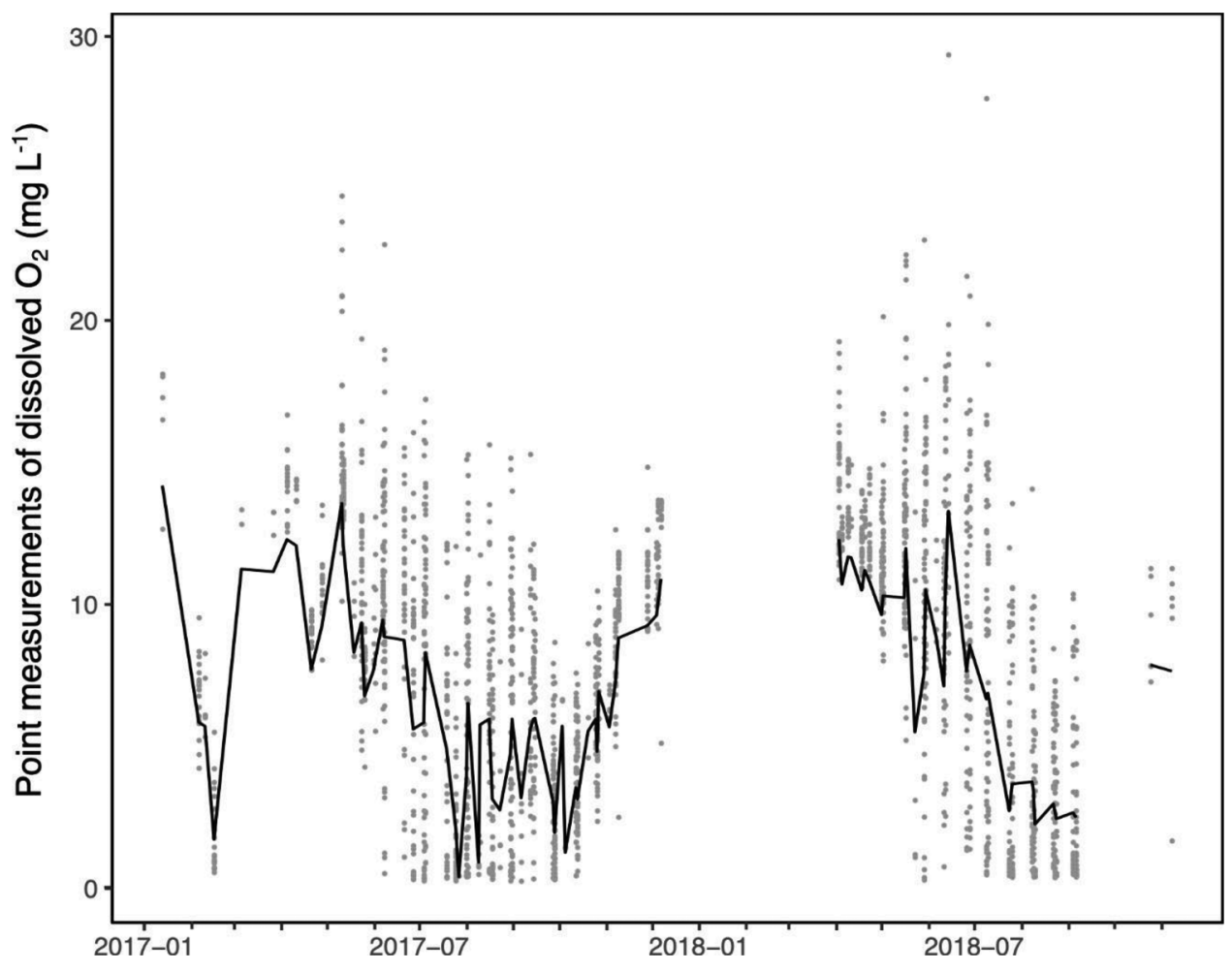

equivalent to the bookkeeping method used in lentic systems (Winslow et al. 2016; eq. 1). Briefly, changes in DO $\left(\mathrm{mg} \cdot \mathrm{L}^{-1} \cdot \mathrm{time}^{-1}\right)$ between consecutive measurements $(\Delta t$, a forward operator in finite difference equations indicating that the time-period considered is $t-1$ to $t$, was 15 to $30 \mathrm{~min})$ were attributed to NEP $\left(\mathrm{mg} \cdot \mathrm{L}^{-1} \cdot\right.$ time $\left.^{-1}\right)$ and gas exchange $\left(\mathrm{mg} \cdot \mathrm{L}^{-1} \cdot\right.$ time $\left.^{-1}\right)$ with the atmosphere:

$$
\Delta \mathrm{DO}=\mathrm{NEP}_{t-1} \times \Delta t+f_{t-1}
$$

where gas exchange between measurements was estimated using eq. 2 from the saturation deficit-surplus of oxygen in the stream water $\left(C_{\text {sat }}=\right.$ concentration of $\mathrm{O}_{2}$ in the water $-\mathrm{O}_{2}$ concentration at saturation in the water; $\mathrm{mg} \cdot \mathrm{L}^{-1}$ ) and the reaeration coefficient (see the following paragraph for details on estimation) for $\mathrm{O}_{2}\left(k ; \mathrm{min}^{-1}\right)$ at stream temperature $\left(T\right.$ in $\left.{ }^{\circ} \mathrm{C}\right)$ and converted from the gas exchange velocity (length. $\mathrm{min}^{-1}$ ) using mean reach depth $(\mathrm{m})$ :

$$
f_{t}=C_{\mathrm{sat}} \times k_{(T)}
$$

Daily NEP rates $\left(\mathrm{g} \mathrm{O}_{2} \cdot \mathrm{m}^{-2}\right.$. day $\left.^{-1}\right)$ were calculated at each site by converting discrete time period NEP rates $\left(\mathrm{g} \mathrm{O}_{2} \cdot \mathrm{m}^{-2} \cdot \Delta \mathrm{t}^{-1}\right)$ in eq. 1 to daily rates and then taking an average of all NEP rates for a given day (the range in number of estimates used in averages was 18 to 51). Net ecosystem production was scaled to areal units using stream stage depth values that were measured using four high frequency (15-min intervals) depth loggers (Fig. 1). Average daily depth measurements for a site were calculated using the nearest depth logger, unless the nearest logger was unavailable, in which case a mean among all depth loggers was used. Note our NEP estimates should be interpreted as relative estimates of NEP over time at each site as we do not scale NEP to mean channel depth at a given site, but rather incorporate site depth as a covariate of mean channel depth in our relative estimates of NEP over time.
We estimated open water season air-water oxygen exchange using a wind-based method for lentic systems (eq. 3; Vachon and Prairie 2013). Atmospheric fluxes of oxygen are caused by DO diffusing into and out of a water body as a function of the saturation of oxygen in water and turbulence at the air-water interface (Bott 2006; Vachon and Prairie 2013). Because the OAC has too low of flow to estimate reaeration coefficients using the standard surface renewal method in streams (i.e., flow $<3 \mathrm{~cm} \cdot \mathrm{s}^{-1}$, Bott 2006), and because the system is essentially stagnant (average flow of only $0.002 \mathrm{~m} \cdot \mathrm{s}^{-1}$, Schincariol et al. 2004) we used a windand ecosystem size-based model developed for use in small lentic systems (Vachon and Prairie 2013). We used the LakeMetabolizer package in $\mathrm{R}$ to fit the gas exchange model (Winslow et al. 2016):

$$
k_{\left(17.5^{\circ} \mathrm{C}\right)}=2.51+1.48 \times U 10+0.39 \times U 10 \times \log _{10} \text { Area }
$$

where $U 10$ is the wind speed $\left(\mathrm{m} \cdot \mathrm{s}^{-1}\right)$ ten meters above the surface of the water and Area is the surface area of the water body $\left(\mathrm{m}^{2}\right)$. Wind speed data was recorded every $15 \mathrm{~min}$ at two weather stations (Fig. 1). Wind speed for a site was based on the nearest weather station, unless the nearest station was unavailable, then the other station was used. The model provides a reaeration coefficient for DO at a water temperature of $17.5^{\circ} \mathrm{C}$ and this was converted to stream temperature at a given time interval using eq. 28.11 in Bott (2006) to correspond with eq. 2.

Our application of Vachon and Prairie (2013)'s wind- and ecosystem size-based approach meets the assumptions of the model, which is independent of the waterbody's shape and was fit to data from waterbodies with similar forested riparian areas as in our study. The only predictor variable, apart from wind speed, in Vachon and Prairie (2013)'s model is waterbody surface area (eq. 3) and our study system's surface area $\left(0.53 \mathrm{~km}^{2}\right)$ is within the range of surface areas included in their data for fitting this model (0.19 to $4.0 \mathrm{~km}^{2}$ ). Vachon and Prairie (2013) found that waterbody 
fetch, which accounts for waterbody shape and wind direction, did not add additional predictive power to their model. They suggested that surface area captures variation in fetch due to wind direction and, therefore, their shape-independent model performed better than one that explicitly include an index of waterbody shape. Nonetheless, our waterbody shape and riparian habitat is similar to Lac Croche (a long, narrow, and forested lake), which was included in their dataset for fitting the model. In light of these considerations, we followed the methods of Vachon and Prairie (2013) in using the entire water body's surface area for calculating reaeration (i.e., not only contributing habitat for each site).

The single station diel oxygen curve method assumes no significant input from groundwater (Bott 2006). We confirmed this assumption was met using methods of Hall and Tank (2005) for determining the bias in our respiration and gross primary production estimates due to potential groundwater discharge. Low DO groundwater inputs influence NEP estimates by artificially inflating community respiration and decreasing gross primary production. Hall and Tank (2005) developed a method for calculating a bias term for both respiration and gross primary productivity estimates. The bias term is a ratio of uncorrected estimates to estimates corrected for groundwater inputs, with a value of 1 indicating no bias (see Appendix A for equations and further details). Hall and Tank (2005) recommended correcting for bias in community respiration estimates if the term was $>1.3$. Further, they reported that a study with gross primary production estimates with bias terms that ranged from 0.88 to 1.09 were not substantially biased by groundwater inputs. We estimated the maximum community respiration and gross primary production bias terms for our study using previously published estimates of groundwater inputs and aquifer DO measurements (see Appendix A for methods and these data). The resulting maximum bias terms for both community respiration and gross primary production were 0.98 . Therefore, based on Hall and Tank (2005), no correction for groundwater input was made in our calculation of NEP as maximum bias terms of community respiration and gross primary production indicated no substantial biases.

\section{Predictors of net ecosystem production}

We tested if the NEP-temperature effects were the same among sites, given site-level variation. Site-level variation in allochthonous carbon inputs or changes in relative biomass of autotrophic versus heterotrophic biomass over time can affect NEP-temperature relationships (Yvon-Durocher et al. 2012), although autotrophs also respire (Hall and Beaulieu 2013). Therefore, we were interested in the spatial consistency of NEP-temperature relationships. We explicitly modeled the effect of water temperature on NEP at each site by estimating separate intercepts and slopes for each site within a single multiple linear regression model. Fitting a single multiple regression model with separate slopes and intercepts by site is preferable over fitting separate regression models for each site because this can inflate type I error. This approach is often referred to as analysis of covariance (ANCOVA) (in this case we included an interaction term to test if effects differ by site). ANCOVA is an appropriate statistical method for our study, which is focused on analyzing the variation within sites using repeated measures, and is not appropriate for analyzing variation among sites (this would require using a mean for each site or controlling for site or subject as a random factor; Bland and Altman 1995; Gelman and Hill 2006).

In addition to water temperature, we considered potential covariates of NEP, including daily precipitation and mean daily air temperature within multiple regression models. We used daily precipitation as a proxy of allochthonous carbon inputs, assuming precipitation events bring allochthonous carbon through surface and groundwater inputs; therefore, we predicted a negative relationship with NEP based on previous work indicating increased respiration with allochthonous carbon inputs (Vachon and del Giorgio 2014). We also considered mean daily air temperature, measured at the nearest weather station, as a proxy of irradiance and predicted a positive relationship between NEP and air temperature based on previous work indicating a positive effect of irradiance on photosynthesis and NEP (Batt and Carpenter 2012). We used the simple approach of using air temperature as a proxy for irradiance, as the two are related (Bristow and Campbell 1984). To account for potential time lags in the effect of water temperature, precipitation, and air temperature on respiration, allochthonous carbon inputs, and photosynthesis respectively, we tested each variable with a 0-, 1-, 2-, 3-, and 4-week time lag. We created a set of candidate multiple regression models that included all predictor variables listed above alone and in combination with the others (we only included noncorrelated predictor variables within the same model) and allowed the effects of those variables to vary or not by site. A total of 192 candidate models were considered and we chose the model that best predicted our response variable using Akaike's information criterion (AIC; Burnham and Anderson 2002). For our estimates of NEP, water temperature, atmospheric oxygen flux, average daily air temperature, and daily precipitation over the study period see Supplemental Information (Supplementary Figs. S1 to S3 ${ }^{1}$ ).

\section{Predictors of observed oxygen dynamics}

To test the ability of NEP to predict hypoxic conditions in the OAC beyond the sites where NEP was estimated, we related NEP to the biweekly DO spot measurements from the 72 sites spread evenly across the OAC (Fig. 2). We fit a regression model that predicted biweekly DO point measurements as a function of NEP at the nearest site where high frequency oxygen loggers were installed. Distances from spot measurements to the nearest oxygen logger site ranged from 0 to $960 \mathrm{~m}$ and the number of spot measurements per site per day ranged from 1 to 11 . A mean of the 1- to 11-point measurements per site were used for each day as the response variable to avoid pseudo replication in the predictor variable. We fit separate intercepts and slopes by site to account for biweekly repeated measures at sites. For two sites where NEP was unrelated to observed oxygen dynamics (see Fig. 4A) we tested if atmospheric oxygen fluxes (i.e., abiotic factors) were significant predictors of oxygen dynamics at these sites. All regression models in our study were fit using the $\operatorname{lm}()$ function in base $\mathrm{R}$ (R Core Team 2020).

\section{Results}

Over the study period dissolved oxygen within the OAC ranged from $0.3-28.9 \mathrm{mg} \cdot \mathrm{L}^{-1}$ (Fig. 2), water temperature ranged from $0.4-$ $35.4{ }^{\circ} \mathrm{C}$, daily precipitation ranged from $0-44.4 \mathrm{~mm}$, and the open water season was from late February to early December (Supplementary Fig. $S 5^{1}$ ).

\section{Predictors of biotic net ecosystem production}

The model with the best ability to predict NEP, based on AIC, contained negative effects of water temperature and a negative effect of precipitation (Fig. 3; see Supplemental Information Table $S 2^{1}$ for the top ten best models). The multiple regression model explained $16 \%$ of the variation in NEP among all sites $(p<0.001)$ and contained average daily water temperature four weeks prior and daily precipitation as predictors. Within the best model, three sites did not have a significant effect of water temperature on NEP (sites 1, 9, and 10; Fig. 3). The same model only containing sites where there were significant effects of water temperature on NEP explained $28 \%$ of the variation in NEP at these sites $(p<0.001)$. The next best model $(\triangle \mathrm{AIC}=14)$ contained the same predictors, but fit a separate effect of daily precipitation by site (Supplementary Table $\mathrm{S1}^{1}$ ). Assuming an average daily precipitation, three sites $(3,11$, and 12$)$ had a range in water temperature 
Fig. 3. (A) Parameter estimates from the best-fitting model that explained $16 \%$ of the variation in biotic net ecosystem production (NEP) among 12 sites listed in ascending site order from upstream to downstream. (B) The effect of average daily water temperature four weeks prior on NEP assuming an average daily precipitation. The strongest model contained a significant, negative effect of daily precipitation on biotic net ecosystem production that was constant among all sites (A). It also contained a significant negative effect of average daily water temperature four weeks prior at 9 of the 12 sites and an insignificant effect at the other three sites (A and B). All solid lines (B) represent significant relationships, while dashed lines represent nonsignificant relationships at the 0.05 level.
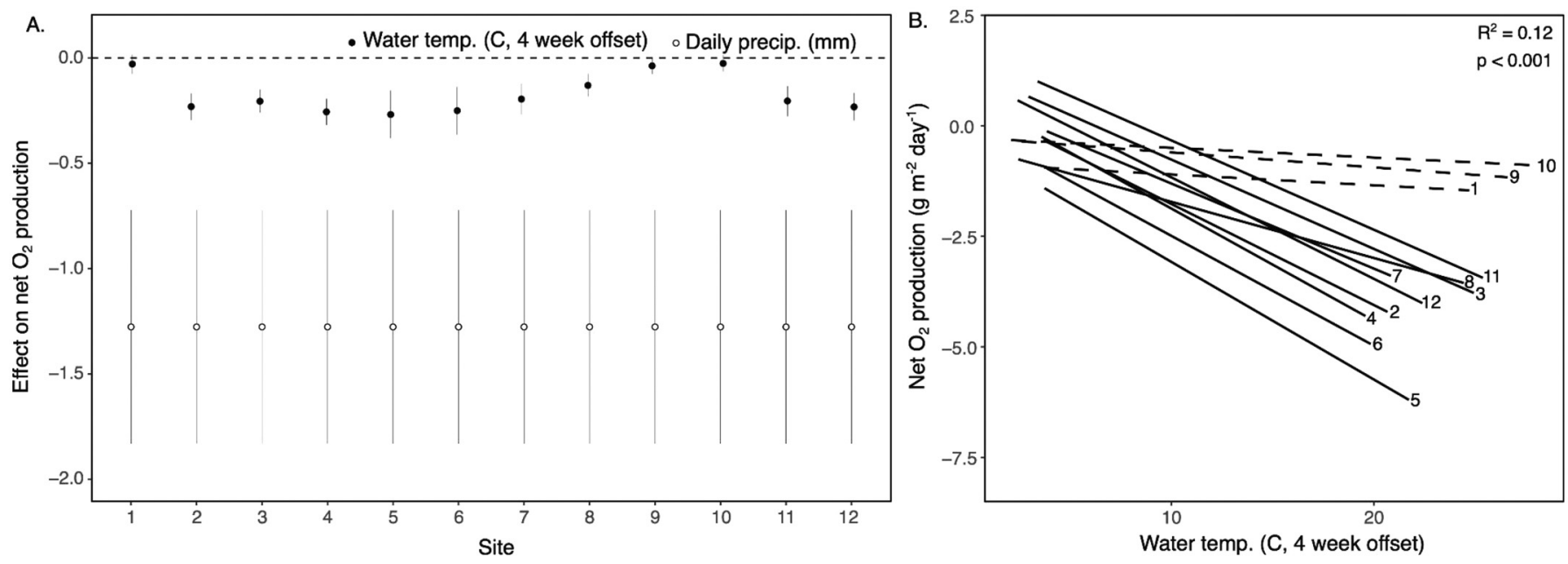

Fig. 4. (A) Net ecosystem production (NEP) of oxygen predicted mean observed dissolved oxygen (DO) point measurements at 10 of 12 sites. (B) Atmospheric flux of oxygen into the watercourse controlled by wind mixing and the saturation of DO in water predicted mean observed DO point measurements in the two sites (10 and 5) where NEP was not a significant predictor. All solid lines represent significant relationships, while dashed lines represent nonsignificant relationships at the 0.05 level.

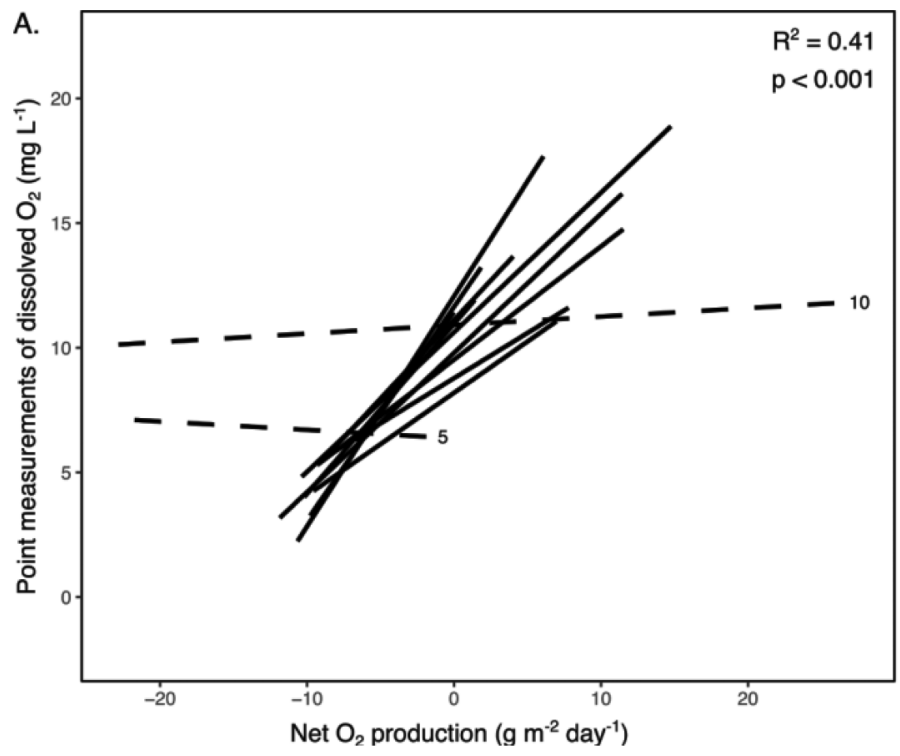

$\left(\sim 4\right.$ to $10^{\circ} \mathrm{C}$ ) where the average NEP was positive (whereas it was negative at higher temperatures), while all other sites had a negative average NEP across the range of observed water temperatures (Fig. 3B). Our best model for predicting NEP contained separate intercepts for each site, suggesting that the relative abundance of heterotrophic to autotrophic biomass varied among sites (Fig. 3A).

The negative effect of increasing water temperature on NEP was consistent among nine sites but was not significant in three of the twelve sites (sites 1, 9, 10; Fig. 3A). The model with the best ability to predict NEP contained varying effects of water temperature by site, the same model but with constant effects of water temperature among sites performed poorly in comparison $(\triangle \mathrm{AIC}=273)$. For 9 of the 12 sites the estimated effects of water temperature on NEP were

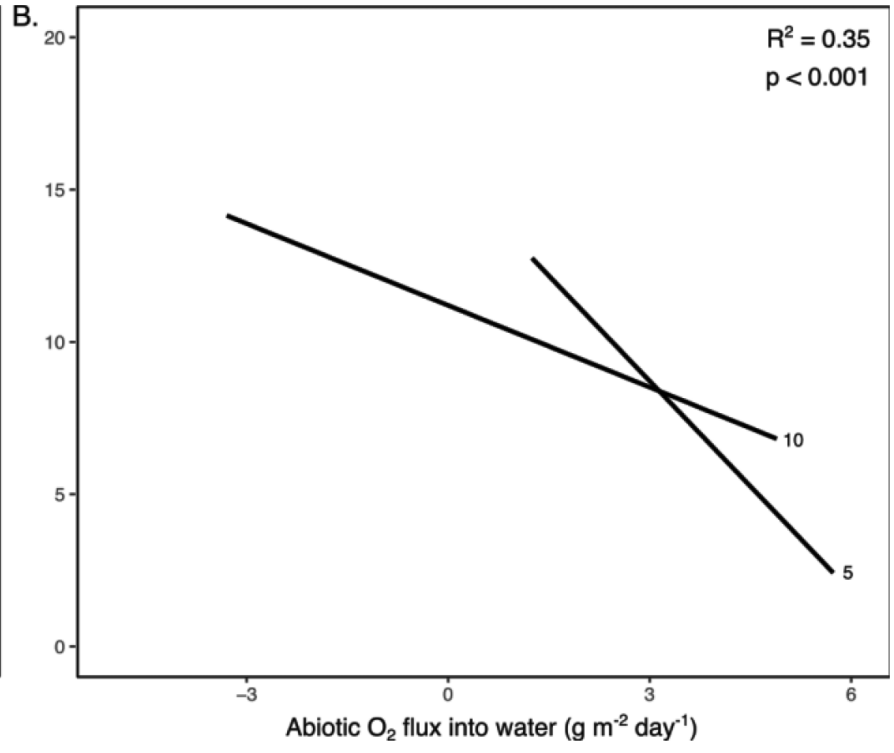

within each other's 95\% confidence intervals, or very close (i.e., sites 4 and 8; Fig. 3A). For the other three sites where water temperature was not a significant predictor, precipitation had a significant negative effect on NEP (Fig. 3A).

\section{Ability of net ecosystem production to predict observed dissolved oxygen}

Net ecosystem production predicted the nearby, spot DO measurements in 10 of the 12 sites, whereas atmospheric factors predicted surrounding observed DO measurements at the other two sites (Fig. 4). Net ecosystem production explained $41 \%$ of the variation in surrounding observed DO among all sites $(p<0.001$; Fig. $4 \mathrm{~A})$ and $44 \%(p<0.001)$ at the 10 sites where NEP was a significant 
predictor. For the two sites where NEP was not a significant predictor of observed DO, atmospheric factors were significant predictors and explained $35 \%$ of the variation in observed DO for the two sites ( $p<0.001$; Fig. $4 \mathrm{~B}$ ). One of the two sites where NEP was not significant (10) also had no relationship between water temperature and NEP. Therefore, at this site precipitation events best predicted NEP and atmospheric factors rather than NEP best predicted oxygen dynamics. Taken together, at eight of twelve sites (67\%), water temperature and precipitation best predicted NEP, explaining $28 \%(p<0.001)$ of the variation in NEP, in turn NEP at these sites explained $40 \%(p<0.001)$ of the variation in nearby mean oxygen dynamics.

For the two sites where NEP was not a significant predictor of independently-measured, observed DO (Fig. 4A), diffusion of oxygen into the watercourse from the atmosphere was negatively correlated to DO ( $p<0.001$; Fig. 4B). Generally speaking, physical effects of air-water gas exchange can decouple gas content in aquatic ecosystems from their metabolic controls (e.g., Vachon et al. (2020) and references therein). Specifically, when DO is supersaturated or undersaturated in the water, atmospheric exchanges lead to a net out- or in-gassing of $\mathrm{O}_{2}$ to the ecosystem, driving DO content toward equilibrium (i.e., 100\% saturation; Vachon et al. 2020). We expect that this physical effect was important at two sites that showed little connection between oxygen content and NEP (dashed lines, Fig. 4A), but which had DO concentrations that strongly correlated with air-water gas exchange (Fig. 4B).

\section{Discussion}

Aquatic species have higher extinction rates compared to terrestrial species (Ricciardi and Rasmussen 1999; Collen et al. 2014) likely because they face multiple anthropogenic stressors, like fragmentation of watercourses and climate change, that can interact to create ecological stressors (Venter et al. 2006). Our approach of using ecosystem metabolism models provides a novel way of integrating multiple effects of human activities to provide new perspectives on the physio-chemical conditions shaping hypoxic stress for species at risk and helps identify biotic and abiotic drivers of hypoxia. We found that water temperatures and precipitation events at $75 \%$ of our sites $(n=9)$ were significantly and negatively correlated to NEP estimates and explained $28 \%$ of the variation in NEP at these sites (16\% of variation when all sites were considered). Further, temperature-induced reductions in NEP at these sites likely contributed to hypoxic conditions threatening the three species at risk in the watercourse as NEP explained $41 \%$ of the variation in mean dissolved oxygen near all sites. While NEP was a significant predictor of independently-measured DO concentrations from nearby locations at $83 \%$ of sites $(n=10)$, atmospheric fluxes of oxygen, regulated by wind and oxygen saturation in water, were better predictors of DO dynamics at the other $17 \%$ of sites $(n=2)$. Altogether, we demonstrate that for this fragmented river channel, water temperature is a contributing factor that can threaten species at risk by creating hypoxic stress during extended periods of warming. Past diversions and installation of a water control structure on the watercourse that has reduced flow has likely exacerbated hypoxia by reducing reaeration.

One explanation for why our best performing model included water temperature 4 weeks prior as a predictor of NEP is that it integrated both the effects of temperature on metabolism and an effect of seasonal warming on the accrual of heterotrophic biomass relative to autotrophic biomass over time. The growth and metabolism of heterotrophic organisms is more temperature sensitive than autotrophic organisms (Allen et al. 2005; Yvon-Durocher et al. 2010). Therefore, if biomass in our study system increased as a function of temperature throughout the growing season, this could have resulted in an accrual of more heterotrophic biomass relative to autotrophic from spring to fall. Consequently, a proportional increase in heterotrophic relative to autotrophic biomass could have resulted in reductions in NEP captured by our time lagged temperature predictor variable. While confirming such an effect of biomass changes on NEP is beyond the scope of the current study, the time-lagged predictor of ecosystem NEP that we have identified here is useful in a monitoring and management context. For example, the simple metric of water temperature may provide an early warning signal (4 weeks in advanced in our case) of hypoxic stress for aquatic species. This would allow time to implement mitigation measures that limit harmful effects of hypoxia on aquatic species.

Here we demonstrated that water temperature is a partial predictor of NEP, which in turn predicts DO content at most of our study sites. This information is useful for guiding monitoring and management of hypoxic stress for aquatic species. Monitoring programs like the one showcased here can reveal the habitat heterogeneity that aquatic species face and can determine where and when hypoxic stress can be predicted and best managed. For example, we identified three sites where there was no relationship between water temperature and NEP, and two sites where abiotic factors like turbulent mixing best predicted DO dynamics. Therefore, management actions that reduced water temperatures at these sites are unlikely to have the intended outcome of increasing NEP and DO. Conversely, at a majority of our sites $(67 \%$ or $n=8$ ) water temperature and precipitation explained $28 \%$ of the variation in NEP and NEP in turn explained $40 \%$ of the variation in nearby oxygen dynamics at those sites. These results suggest that management actions aimed at reducing water temperatures at these sites could have a noticeable, positive effect on DO content. Even though the variation explained in each relationship is low, a small effect on DO at a site could be biologically significant if the effect causes DO to cross a critical threshold for aquatic species, or reduces the duration of hypoxia.

Our results may be applicable to other fragmented, low-flow systems where water temperature increases caused by urban land-use and climate change occur, and suggest that these anthropogenic activities may limit the availability of hypoxia refuge for aquatic species. Rivers in urbanized areas experience increased water temperatures that are further intensified by climate change (Nelson and Palmer 2007). One estimate from a watershed near our study system suggested that increased urbanization and air temperatures since European settlement has led to a $27 \%$ decrease in the prevalence of cold water streams in the region, with prevalence expected to further decrease to $50 \%$ over the next 50 years (Di Rocco et al. 2016). Similar to Demars et al. (2011), we found a negative effect of stream temperature on NEP, but unlike Demars et al. (2011), who only observed heterotrophic streams (NEP ranging from -3 to $-67 \mathrm{~g} \mathrm{O}_{2} \cdot \mathrm{m}^{-2}$. $\mathrm{day}^{-1}$ ), we often observed net oxygen production during our study, with $27 \%$ of days on average among sites having positive NEP (NEP ranged from 27 to $-36 \mathrm{~g} \mathrm{O}_{2} \cdot \mathrm{m}^{-2}$. day $^{-1}$ in our study). Further, at three sites we observed that when the water temperature was below $\sim 10^{\circ} \mathrm{C}$ there was net oxygen production on average but above $10{ }^{\circ} \mathrm{C}$ these sites shifted to net oxygen consumption (Fig. 3). These 3 sites may serve as refuges from hypoxia within the channel because they were less susceptible to heterotrophy compared to other sites (Fig. 3). However, our finding of a significant negative relationship between water temperature and NEP at $75 \%$ of our sites, combined with findings that urbanization and climate change will likely continue to increase stream temperature, suggest that hypoxia refuges may be lost as water temperatures continue to increase and shift sites to more heterotrophic conditions. The effect of warming on NEP must be considered alongside numerous other factors that will interact or override temperature as a predictor of NEP, as indicated by the moderate-to-low variance explained in our multiple regression model of NEP-temperature relationships among sites.

Precipitation events can increase the delivery of allochthonous carbon, thereby increasing heterotrophic biomass and activity 
(Yvon-Durocher et al. 2012; Vachon and del Giorgio 2014), which is consistent with our finding of significant negative effects of precipitation events on NEP at all sites. In two sites where water temperature was not a significant predictor of NEP but precipitation events were predictors (sites 9 and 10), strong upwelling frequently occurs after precipitation events near these sites resulting in high turbidity, and this is not observed elsewhere in the channel (Schincariol et al. 2004). Therefore, following precipitation events, periodic inputs of allochthonous carbon and increased shading of autotrophs from turbidity caused by upwelling at these sites may have confounded NEP-temperature relationships and could explain why precipitation events were negatively related to and better predicted NEP at these sites (i.e., precipitation events supplying organic carbon in runoff that is then respired or shading decreasing photosynthesis would result in decreased NEP with precipitation events).

Our work represents a promising first step towards integrating theory on the temperature dependence of whole ecosystem metabolism and relevant temperature-dependent physiological requirements for fish based on their metabolic demands. A fish's aerobic scope (the difference between an individual's base and maximum metabolic rate), which measures their ability to cope with environmental demands, is generally a bell-shaped curve with increasing water temperatures (Fry 1971; McBryan et al. 2013). Therefore, there is a maximum aerobic scope over a range of temperatures, and an associated optimal temperature at this maximum, where a fish is best able to deal with environmental demands. In general, hypoxia reduces the aerobic scope at a given temperature, thereby decreasing the maximum aerobic scope a species experiences at their optimum temperature (Claireaux and Chabot 2016; see also McBryan et al. (2013) for a review of this literature). Potts et al. (2021) found that the critical thermal maximum temperature where pugnose shiner (one of the species at risk in the $\mathrm{OAC}$ ) lost equilibrium decreased when they were exposed to hypoxia, suggesting the species' aerobic scope may also be sensitive to hypoxia. Taken together, temperature can predict both the NEP within a watercourse (the likelihood of hypoxic conditions) as well as the aerobic scope for a given fish species (their ability to deal with environmental demands). However, as we demonstrate in this study, integrating both whole ecosystem metabolism and aerobic scope of fish will involve considerations of the spatial and temporal variation of NEP covariates and the influence of atmospheric and hydrologic factors on DO. Further considerations include the ability of fish species to adapt to low oxygen and or thermal regimes (Chrétien and Chapman 2016; Potts et al. 2021), and the sensitivity of species-specific thermal tolerance to hypoxia (Ern et al. 2016; Potts et al. 2021).

The causes of hypoxia in aquatic systems are often diverse and can be system specific (Mallin et al. 2006), but our results demonstrate that water temperature can be a contributing factor leading to hypoxic stress for fish species at risk in low-flow, fragmented river systems. Therefore, recovery measures for species at risk that include restoration of turbulent mixing (i.e., flow and reaeration; Palmer and Ruhi 2019), planting of riparian vegetation that shades reaches of the water course and reduces water temperatures (Fugère et al. 2018), and reducing warm storm water runoff from urban areas (Nelson and Palmer 2007) is likely to reduce hypoxic stress for aquatic species. These measures may lead to greater DO concentrations both through physical effects on DO saturation but also through limiting heterotrophy and DO consumption.

\section{Conclusion}

In our study we showed that increased water temperature throughout much of our study system had a predictable effect of increasing hypoxic stress for fish by reducing NEP. Even though NEP was not explained by water temperature at three of our twelve sites, NEP was a strong predictor of dissolved oxygen concentrations within our study system (i.e., it explained $41 \%$ of the variation in dissolved oxygen concentrations among all sites). Therefore, insights from ecosystem metabolism models are useful for predicting hypoxic stress for aquatic species in low-flow fragmented river systems where atmospheric diffusion of $\mathrm{O}_{2}$ is limited. These results have applications for understanding threats to aquatic species at risk, integrating theory on ecosystem metabolism and the aerobic scope of fishes, and modeling future effects of climate change on aquatic species. However, understanding spatial and temporal variability in covariates of NEP and the importance of atmospheric and hydrologic factors for structuring oxygen dynamics within ecosystems is important when considering using system wide predictors of hypoxic stress based on ecosystem metabolism models.

\section{Acknowledgements}

Funding for this study was provided by Fisheries and Oceans Canada's Species at Risk Program. We thank the individuals who undertook logger deployment and other field measurements, including Kari Jean, Jeff Van Niekerk, Tony Drinkwalter, and Leslie Coleman at the Ausable Bayfield Conservation Authority. J. Ziegler was supported by funding from Fisheries and Oceans Canada's Partnership Program as part of the Canadian Freshwater Species at Risk Research Network. M. Bogard is supported by funds from the Canada Research Chairs program and the University of Lethbridge.

\section{References}

Allen, A.P., Gillooly, J.F., and Brown, J.H. 2005. Linking the global carbon cycle to individual metabolism. Funct. Ecol. 19(2): 202-213. doi:10.1111/j.13652435.2005.00952.x.

Arroita, M., Elosegi, A., and Hall, R. 2019. Twenty years of daily metabolism show riverine recovery following sewage abatement. Limnol. Oceanogr. 64: S77-S92. doi:10.1002/lno.11053.

Batt, R.D., and Carpenter, S.R. 2012. Free-water lake metabolism: addressing noisy time series with a Kalman filter. Limnol. Oceanogr. Methods, 10: 20-30. doi:10.4319/lom 2012.10.20.

Beechie, T.J., Sear, D.A., Olden, J.D., Pess, G.R., Buffington, J.M., Moir, H., et al. 2010. Process-based principles for restoring river ecosystems. BioScience, 60: 209-222. doi:10.1525/bio.2010.60.3.7.

Bland, J.M., and Altman, G.G. 1995. Calculating correlation coefficients with repeated observations: part 2 - correlation between subjects. BMJ, 310: 633 . doi:10.1136/bmj.310.6980.633.

Bogard, M.J., St-Gelais, N.F., Vachon, D., and del Giorgio, P.A. 2020. Patterns of Spring/Summer Open-Water Metabolism across Boreal Lakes. Ecosystems, 23: 1581-1597. doi:10.1007/s10021-020-00487-7.

Bott, T.L. 2006. Primary productivity and community respiration. In Methods in Stream Ecology. Edited by F.R. Hauer and G. Lamberti. Academic Press, London, UK. pp. 663-690.

Bristow, K.L., and Campbell, G.S. 1984. On the relationship between incoming solar radiation and daily maximum and minimum temperature. Agric. For. Meteorol. 31: 159-166. doi:10.1016/0168-1923(84)90017-0.

Bunn, S.E., and Arthington, A.H. 2002. Basic principles and ecological consequences of altered flow regimes for aquatic biodiversity. Environ. Manage. 30: 492-507. doi:10.1007/s00267-002-2737-0. PMID:12481916.

Burnham, K.P., and Anderson, D.R. 2002. Model selection and multimodel inference: a practical information-theoretic approach. 2nd ed. Springer, New York.

Chrétien, E., and Chapman, L.J. 2016. Tropical fish in a warming world: thermal tolerance of Nile perch Lates niloticus (L.) in Lake Nabugabo, Uganda. Conserv. Physiol. 4: cow062. doi:10.1093/conphys/cow062.

Claireaux, G., and Chabot, D. 2016. Responses by fishes to environmental hypoxia: integration through Fry's concept of aerobic metabolic scope. J. Fish Biol. 88: 232-251. doi:10.1111/jfb.12833. PMID:26768976.

Clark, T.D., Sandblom, E., and Jutfelt, F. 2013. Aerobic scope measurements of fishes in an era of climate change: respirometry, relevance and recommendations. J. Exp. Biol. 216: 2771-2782. doi:10.1242/jeb.084251.

Collen, B., Whitton, F., Dyer, E.E., Baillie, J.E., Cumberlidge, N., Darwall, W.R., et al. 2014. Global patterns of freshwater species diversity, threat and endemism. Glob. Ecol. Biogeogr. 23: 40-51. doi:10.1111/geb.12096. PMID:26430385.

Del Giorgio, P.A., Cole, J.J., Caraco, N.F., and Peters, R.H. 1999. Linking planktonic biomass and metabolism to net gas fluxes in northern temperate lakes. Ecology, 80: 1422-1431. doi:10.1890/0012-9658(1999)080[1422: LPBAMT]2.0.CO;2. 
Demars, B.O.L., Manson, J.R., Ólafsson, J.S., Gíslason, G.M., Gudmundsdóttir, R., Woodward, G., et al. 2011. Temperature and the metabolic balance of streams. Freshw. Biol. 56: 1106-1121. doi:10.1111/j.1365-2427.2010.02554.x.

Demars, B.O.L., Gíslason, G.M., Ólafsson, J.S., Manson, J.R., Friberg, N., Hood, J.M., et al. 2016. Impact of warming on $\mathrm{CO}_{2}$ emissions from streams countered by aquatic photosynthesis. Nat. Geosci. 9: 758-761. doi:10.1038/ ngeo2807.

Di Rocco, R.T., Jones, N.E., and Chu, C. 2016. Past, present, and future summer stream temperature in the Lake Simcoe watershed: brook trout (Salvelinus fontinalis) habitat at risk. Climate Change Research Report CCRR-45. Ontario Ministry of Natural Resources and Forestry, Science and Research Branch, Peterborough, Ont.

Diaz, R.J., and Breitburg, D.L. 2009. The hypoxic environment. Fish Physiol. 27: 1-23. doi:10.1016/S1546-5098(08)00001-0.

Döll, P., Fiedler, K., and Zhang, J. 2009. Global-scale analysis of river flow alterations due to water withdrawals and reservoirs. Hydrol. Earth Syst. Sci. 13: 2413-2432. doi:10.5194/hess-13-2413-2009.

Dynesius, M., and Nilsson, C. 1994. Fragmentation and flow regulation of river systems in the northern third of the world. Science, 266: 753-762. doi:10.1126/science.266.5186.753. PMID:17730396.

Enquist, B.J., Economo, E.P., Huxman, T.E., Allen, A.P., Ignace, D.D., and Gillooly, J.F. 2003. Scaling metabolism from organisms to ecosystems. Nature, 423: 639-642. doi:10.1038/nature01671. PMID:12789338.

Ern, R., Norin, T., Gamperl, A.K., and Esbaugh, A.J. 2016. Oxygen dependence of upper thermal limits in fishes. J. Exp. Biol. 219: 3376-3383. doi:10.1242 jeb.143495. PMID:27591316.

Fry, F.E.J. 1971. The effect of environmental factors on the physiology of fish. Fish Physiol. 1-98. doi:10.1016/S1546-5098(08)60146-6.

Fugère, V., Mehner, T., and Chapman, L.J. 2018. Impacts of deforestationinduced warming on the metabolism, growth and trophic interactions of an afrotropical stream fish. Funct. Ecol. 32: 1343-1357. doi:10.1111/13652435.13065 .

Gelman, A., and Hill, J. 2006. Data analysis using regression and multilevel/ hierarchical models. Cambridge University Press, Cambridge, UK.

Genzoli, L., and Hall, R.O., Jr. 2016. Shifts in Klamath River metabolism following a reservoir cyanobacterial bloom. Freshw. Sci. 35: 795-809. doi:10.1086/687752.

Grill, G., Lehner, B., Thieme, M., Geenen, B., Tickner, D., Antonelli, F., et al. 2019. Mapping the world's free-flowing rivers. Nature, 569: 215-221. doi:10.1038/s41586-019-1111-9. PMID:31068722.

Hall, R.O., and Beaulieu, J.J. 2013. Estimating autotrophic respiration in streams using daily metabolism data. Freshw. Sci. 32: 507-516. doi:10.1899/12-147.1.

Hall, R.O., and Tank, J.L. 2005. Correcting whole-stream estimates of metabolism for groundwater input. Limnol. Oceanogr. Methods, 3: 222-229. doi:10.4319/lom.2005.3.222.

Inkscape Project. 2020. Inkscape. Available from https://inkscape.org.

Jankowski, K., Schindler, D.E., and Lisi, P.J. 2014. Temperature sensitivity of community respiration rates in streams is associated with watershed geomorphic features. Ecology, 95: 2707-2714. doi:10.1890/14-0608.1.

Lorenz, A.W., Haase, P., Januschke, K., Sundermann, A., and Hering, D. 2018. Revisiting restored river reaches - assessing change of aquatic and riparian communities after five years. Sci. Total Environ. 613: 11 85-1195. doi:10.1016/j. scitotenv.2017.09.188. PMID:28954379.

Mallin, M.A., Johnson, V.L., Ensign, S.H., and MacPherson, T.A. 2006. Factors contributing to hypoxia in rivers, lakes, and streams. Limnol. Oceanogr. 51: 690-701. doi:10.4319/1o.2006.51.1 part 2.0690.

McBryan, T.L., Anttila, K., Healy, T.M., and Schulte, P.M. 2013. Responses to temperature and hypoxia as interacting stressors in fish: implications for adaptation to environmental change. Integr. Comp. Biol. 53: 648-659. doi:10.1093/icb/ict066. PMID:23784697.

Nelson, K.C., and Palmer, M.A. 2007. Stream temperature surges under urbanization and climate change: data, models, and responses. J. Am. Water Resour. Assoc. 43: 440-452. doi:10.1111/j.1752-1688.2007.00034.x.

Owens, M., Edwards, R.W., and Gibbs, J.W. 1964. Some reaeration studies in streams. Air Water Pollut. 8: 469-486. PMID:14215805.

Palmer, M., and Ruhi, A. 2019. Linkages between flow regime, biota, and ecosystem processes: Implications for river restoration. Science, 365: eaaw2087. doi:10.1126/science.aaw2087. PMID:31604208.

Palmer, M.A., Hondula, K.L., and Koch, B.J. 2014. Ecological restoration of streams and rivers: shifting strategies and shifting goals. Annu. Rev. Ecol. Evol. Syst. 45: 247-269. doi:10.1146/annurev-ecolsys-120213-091935.

Pérez-Fuentetaja, A., Dillon, P.J., Yan, N.D., and McQueen, D.J. 1999. Significance of dissolved organic carbon in the prediction of thermocline depth in small Canadian shield lakes. Aquat. Ecol. 33: 127-133. doi:10.1023/ A:1009998118504.

Poff, N.L., Allan, J.D., Bain, M.B., Karr, J.R., Prestegaard, K.L., Richter, B.D., et al. 1997. The natural flow regime. BioScience, 47: 769-784. doi:10.2307| 1313099.

Poff, N.L., Olden, J.D., Merritt, D.M., and Pepin, D.M. 2007. Homogenization of regional river dynamics by dams and global biodiversity implications. Proc. Natl. Acad. Sci. U.S.A. 104: 5732-5737. doi:10.1073/pnas.0609812104. PMID:17360379.

Potts, L., Mandrak, N.M., and Chapman, L.J. 2021. Phenotypic plasticity in the imperiled Pugnose Shiner (Notropis anogenus) in response to elevated water temperature. Aquat. Conserv. [in press]. doi:10.1002/aqc.3620.
R Core Team. 2020. R: a language and environment for statistical computing. R Foundation for Statistical Computing, Vienna, Austria. Available from https://www.R-project.org/.

Regaudie-de-Gioux, A., and Duarte, C.M. 2012. Temperature dependence of planktonic metabolism in the ocean. Glob. Biogeochem. Cycles, 26. doi:10.1029/2010GB003907.

Ricciardi, A., and Rasmussen, J.B. 1999. Extinction rates of North American freshwater fauna. Conserv. Biol. 13: 1220-1222. doi:10.1046/j.1523-1739.1999.98380.x.

Roy, J.W., and Malenica, A. 2013. Nutrients and toxic contaminants in shallow groundwater along Lake Simcoe urban shorelines. Inland Waters, 3: 125-138. doi:10.5268/IW-3.2.521.

Schincariol, R.A., Maun, M.A., Steinbachs, J.N., Wiklund, J.A., and Crowe, A.C. 2004. Response of an aquatic ecosystem to human activity: hydro-ecology of a river channel in a dune watershed. J. Freshw. Ecol. 19: 123-139. doi:10.1080/ 02705060.2004.9664520.

Schramski, J.R., Dell, A.I., Grady, J.M., Sibly, R.M., and Brown, J.H. 2015. Metabolic theory predicts whole-ecosystem properties. Proc. Natl. Acad. Sci. U.S.A. 112: 2617-2622. doi:10.1073/pnas.1423502112. PMID:25624499.

Sitters, J., Atkinson, C.L., Guelzow, N., Kelly, P., and Sullivan, L.L. 2015. Spatial stoichiometry: cross-ecosystem material flows and their impact on recipient ecosystems and organisms. Oikos, 124: 920-930. doi:10.1111/oik.02392.

Solomon, C.T., Carpenter, S.R., Clayton, M.K., Cole, J.J., Coloso, J.J., Pace, M.L., et al. 2011. Terrestrial, benthic, and pelagic resource use in lakes: results from a three-isotope Bayesian mixing model. Ecology, 92: 1115-1125. doi:10.1890/10-1185.1. PMID:21661572.

Song, C., Dodds, W.K., Rüegg, J., Argerich, A., Baker, C.L., Bowden, W.B., et al. 2018. Continental-scale decrease in net primary productivity in streams due to climate warming. Nat. Geosci. 11: 415-420. doi:10.1038/s41561-018-0125-5.

Stanford, J.A., and Nelson, P.C. 1997. Instream flows to assist the recovery of endangered fishes of the Upper Colorado River Basin. Edited by P.A. Opler, P.A. Vohs, E.D. Rockwell, J.R. Zuboy, D.K. Harris, C.M. Lemos, and D.D. Tait. US Fish and Wildlife Services, Washington, D.C.

Tsivoglou, E.C., and Neal, L.A. 1976. Tracer measurement of reaeration: III. Predicting the reaeration capacity of inland streams. J. Water Pollut. Control Fed. 48(12): 2669-2689. Available from https://www.jstor.org/stable/25040082.

Ulseth, A.J., Hall, R.O., Canadell, M.B., Madinger, H.L., Niayifar, A., and Battin, T.J. 2019. Distinct air-water gas exchange regimes in low- and high-energy streams. Nat. Geosci. 12: 259-263. doi:10.1038/s41561-019-0324-8.

Vachon, D., and del Giorgio, P.A. 2014. Whole-lake $\mathrm{CO}_{2}$ dynamics in response to storm events in two morphologically different lakes. Ecosystems, 17: 13381353. doi:10.1007/s10021-014-9799-8.

Vachon, D., and Prairie, Y.T. 2013. The ecosystem size and shape dependence of gas transfer velocity versus wind speed relationships in lakes. Can. J. Fish. Aquat. Sci. 70(12): 1757-1764. doi:10.1139/cjfas-2013-0241.

Vachon, D., Sadro, S., Bogard, M.J., Lapierre, J.F., Baulch, H.M., Rusak, J.A., et al. 2020. Paired $\mathrm{O}_{2}-\mathrm{CO}_{2}$ measurements provide emergent insights into aquatic ecosystem function. Limnol. Oceanogr. Lett. 5(4): 287-294. doi:10.1002/lol2.10135.

Venter, O., Brodeur, N.N., Nemiroff, L., Belland, B., Dolinsek, I.J., and Grant, J.W. 2006. Threats to endangered species in Canada. Bioscience, 56: 903-910. doi:10.1641/0006-3568(2006)56[903:TTESIC]2.0.CO;2.

Webb, B.W., Clack, P.D., and Walling, D.E. 2003. Water-air temperature relationships in a Devon river system and the role of flow. Hydrol. Process, 17: 3069-3084. doi:10.1002/hyp.1280.

Winslow, L.A., Zwart, J.A., Batt, R.D., Dugan, H.A., Woolway, R.I., Corman, J.R., et al. 2016. Lake Metabolizer: an R package for estimating lake metabolism from free-water oxygen using diverse statistical models. Inland Waters, 6: 622-636. doi:10.1080/IW-6.4.883.

Yvon-Durocher, G., Jones, J.I., Trimmer, M., Woodward, G., and Montoya, J.M. 2010. Warming alters the metabolic balance of ecosystems. Philos. Trans. R Soc. Lond. B Biol. Sci. 365: 2117-2126. doi:10.1098/rstb.2010.0038. PMID: 20513719.

Yvon-Durocher, G., Caffrey, J.M., Cescatti, A., Dossena, M., Giorgio, P.D., Gasol, J.M., et al. 2012. Reconciling the temperature dependence of respiration across timescales and ecosystem types. Nature, 487: 472-476. doi:10.1038/nature11205. PMID:22722862.

\section{Appendix A. Estimating bias in community respiration from groundwater}

To determine the bias in our community respiration and gross primary production estimates due to groundwater inputs, we followed the methods of Hall and Tank (2005). For community respiration, bias $\left(B_{C R}\right)$ is a function of uncorrected community respiration (CR), the concentration of oxygen in the groundwater $\left(C_{\mathrm{g}}\right)$, the concentration of oxygen in the stream $\left(C_{\mathrm{s}}\right)$, and groundwater discharge per metre squared $(Q)$ :

\section{(A1) $\quad B_{\mathrm{CR}}=\mathrm{CR} /\left\{\mathrm{CR}-\left[\left(C_{\mathrm{g}}-C_{\mathrm{s}}\right) \mathrm{Q}\right]\right\}$}

For gross primary production, bias $\left(B_{\mathrm{GP}}\right)$ is a function of uncorrected gross primary production (GPP), uncorrected community respiration, the concentration of oxygen in the stream during the day $\left(C_{\mathrm{d}}\right)$, the 
Fig. A1. Average dissolved oxygen (DO) concentrations within groundwater aquifers significantly decrease at downstream sites in the Old Ausable Channel (OAC; see Fig. 1 for location of sites). Data are from Golder Associates (2011); point estimates are an average of 9 monthly DO measures of aquifers measured at wells near the reported sites. The lowest observed point estimate of aquifer DO was $0 \mathrm{mg} \cdot \mathrm{L}^{-1}$ and was used in eq. A1 above. Vertical lines are $95 \%$ confidence intervals. Note that DO may be lower in groundwater by the time it reaches and discharges to the OAC.

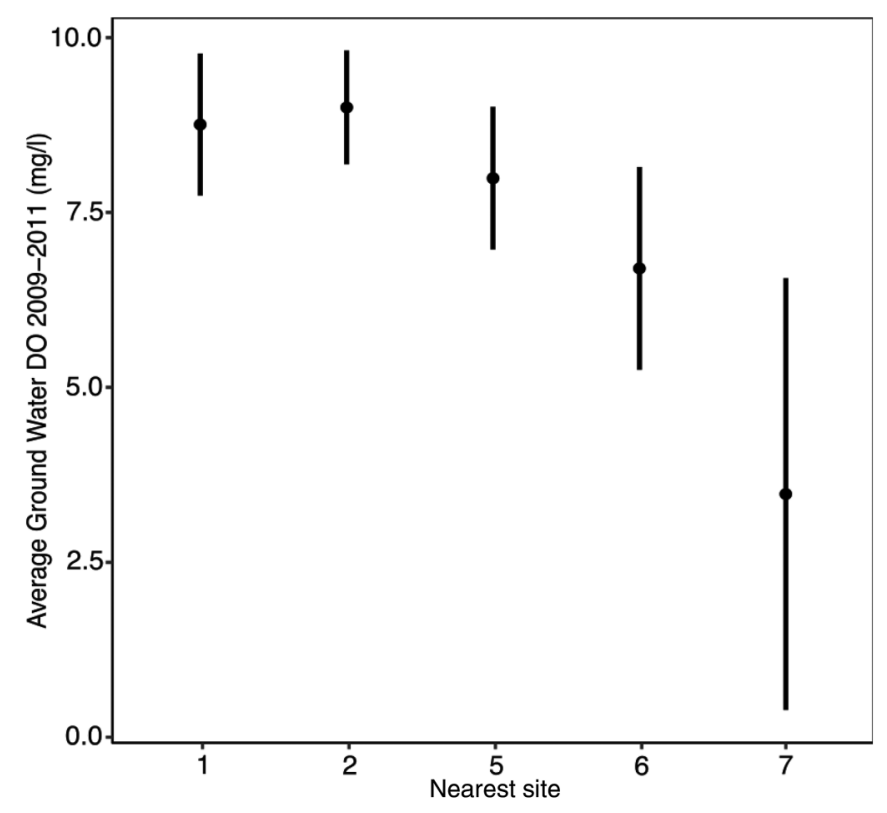

concentration of oxygen in the stream during the night $\left(C_{n}\right)$, and groundwater discharge per metre squared $(Q)$ :

$$
B_{\mathrm{GP}}=\mathrm{GPP} /\left\{\mathrm{GPP}+\left[\left(C_{\mathrm{d}}-C_{\mathrm{n}}\right) Q\right]\right\}
$$

The greatest bias in community respiration occurs when there is a high groundwater discharge and a large difference in oxygen concentration between groundwater and stream water (Hall and
Tank 2005). Similarly, the greatest bias in gross primary production occurs when there is a high groundwater discharge and a large difference in stream daytime and nighttime oxygen concentration (Hall and Tank 2005). Therefore, to estimate maximum bias terms we used observed parameters for our study system that would result in the greatest bias. For community respiration (eq. A1) we used the highest groundwater flow into our study stream (vertical velocity) measured by Schincariol et al. (2004) $\left(3.16 \times 10^{-6} \mathrm{~m} \cdot \mathrm{min}^{-1}\right)$, the highest stream water dissolved oxygen concentration observed during our study (29.35 mg. $\mathrm{L}^{-1}$ ), the lowest groundwater dissolved oxygen concentration observed for our study stream by Golder Associates (2011) (0 mg. $\mathrm{L}^{-1}$; see Fig. A1 for a summary of mean groundwater dissolved oxygen by site), and a mean of all community respiration estimates observed during our study $\left(0.005 \mathrm{mg} \cdot \mathrm{L}^{-1} \cdot \mathrm{min}^{-1}\right)$. For gross primary production (eq. A2) we used the highest groundwater flow into our study stream (vertical velocity) measured by Schincariol et al. (2004) $\left(3.16 \times 10^{-6} \mathrm{~m} \cdot \mathrm{min}^{-1}\right)$, the highest daytime stream water dissolved oxygen concentration observed during our study $\left(29.35 \mathrm{mg} \cdot \mathrm{L}^{-1}\right)$, the lowest nighttime stream water dissolved oxygen concentration observed during our study $\left(0 \mathrm{mg} \cdot \mathrm{L}^{-1}\right)$, and a mean of all gross primary production estimates observed during our study $\left(0.0039 \mathrm{mg} \cdot \mathrm{L}^{-1} \cdot \mathrm{min}^{-1}\right)$.

For our study the resulting maximum bias term estimates for community respiration and gross primary production were 0.98 for both terms, with an estimate of 1 indicating no bias. Hall and Tank (2005) recommended correcting for bias in community respiration if $B_{C R}>1.3$. Further, they reported that a study with gross primary production estimates with bias terms $\left(B_{\mathrm{GP}}\right)$ that ranged from 0.88 to 1.09 were not substantially biased. Therefore, no correction for groundwater input was made in our calculation of NEP as our maximum estimates of $B_{C R}$ and $B_{\mathrm{GP}}$ indicated no substantial bias.

\section{References}

Golder Associates. 2011. Groundwater monitoring wells: community of Grand Bend Municipality of Lambton Shores, Ontario. Report No. 08-1132116-0-R03.

Hall, R.O., and Tank, J.L. 2005. Correcting whole-stream estimates of metabolism for groundwater input. Limnol. Oceanogr. Methods, 3: 222-229. doi:10.4319/lom.2005.3.222.

Schincariol, R.A., Maun, M.A., Steinbachs, J.N., Wiklund, J.A., and Crowe, A.C. 2004. Response of an aquatic ecosystem to human activity: hydro-ecology of a river channel in a dune watershed. J. Freshw. Ecol. 19: 123-139. doi:10.1080/ 02705060.2004.9664520. 